\title{
Response delays and the timing of discrete motor responses*
}

\author{
ALAN M. WING and A. B. KRISTOFFERSON \\ McMaster University, Hamilton, Ontario, Canada
}

\begin{abstract}
A model for the timing of repetitive discrete motor responses is proposed, and a prediction of negative dependency between successive interresponse intervals is confirmed by data from a Morse key tapping task. A method that makes use of the first-order serial correlation between interresponse intervals is used to distinguish between variance due to a timekeeping process and variance in motor response delays subsequent to the timekeeper. These two quantities are examined as a function of mean interresponse interval.
\end{abstract}

For simple skills such as the periodic tapping of a Morse telegraph key where the response of key closure is easily produced and is repeatable, successive responses may be used to define a chain of interresponse intervals. Wing and Kristofferson (1973) have examined the relation between interresponse interval mean and variance for experiments in which highly trained Ss produced many such sequences of interresponse intervals in the range from 170 through $350 \mathrm{msec}$. To account for the observed function, they proposed a mechanism for the timing of discrete responses with two distinct processes (see Fig. 1). At intervals, $C_{j}$, a timekeeping process is assumed to generate trigger pulses, each of which initiates a motor response. In addition, to allow for the effects of, for example, neuromuscular transmission lags, movement time, etc., a delay process is assumed. Thus, subsequent to the $\mathrm{j}^{\mathrm{t} \text { th }}$ trigger pulse, there is a delay, $D_{j}$, before the response is observed. In this paper, we assume that $C$ and $D$ are independent random variables with means, $\mu_{\mathrm{C}}$ and $\mu_{\mathrm{D}}$, and variances, $\sigma_{\mathrm{C}}^{2}$ and $\sigma_{\mathrm{D}}^{2}$, respectively. The $\mathrm{j}^{\text {th }}$ interresponse interval (assumed greater than zero) is given by:

$$
\mathrm{I}_{\mathrm{j}}=\mathrm{C}_{\mathrm{j}}-\mathrm{D}_{\mathrm{j}-1}+\mathrm{D}_{\mathrm{j}}
$$

with mean, $\mu_{\mathrm{I}}=\mu_{\mathrm{C}}$, and variance, $\sigma_{\mathrm{I}}^{2}$.

McGill (1962) has suggested the special case of this model, for which $\sigma_{\mathbf{C}}^{2}=0$, as an account of rate fluctuations in, for example, the action potentials of the horseshoe crab optic nerve. If it is assumed that D is exponentially distributed, it can be shown that I should have the Laplace distribution, and he presented data with I distributions of this form as support for the model.

The lag one serial correlation, $\rho_{\mathrm{I}}(1)$, may be used as a measure of the statistical dependence between successive interresponse intervals. It is defined:

\footnotetext{
*This research was supported by Grant A7919 from the National Research Council of Canada. The authors wish to thank Saul Sternberg for his critical comments on an earlier draft of this paper.
}

$$
\rho_{\mathbf{I}}(1)=\frac{\gamma_{\mathbf{I}}(1)}{\gamma_{\mathbf{I}}(0)}
$$

where the lag one covariance, $\gamma_{\mathbf{I}}(1)$, is defined as the expectation over all intervals of the product of the deviation of one interresponse interval about the mean and the deviation of the immediately preceding interval about the mean:

$$
\begin{aligned}
\gamma_{\mathrm{I}}(1)= & E\left[\left(\mathrm{I}_{\mathrm{j}}-\mu_{\mathrm{I}}\right)\left(\mathrm{I}_{\mathrm{j}-1}-\mu_{\mathrm{I}}\right)\right] ; \mathrm{j}=\cdots,-1,0,+1, \cdots \\
= & E\left[\left(\mathrm{C}_{\mathrm{j}}-\mathrm{D}_{\mathrm{j}-1}+\mathrm{D}_{\mathrm{j}}-\mu_{\mathrm{I}}\right)\right. \\
& \left.\cdot\left(\mathrm{C}_{\mathrm{j}-1}-\mathrm{D}_{\mathrm{j}-2}+\mathrm{D}_{\mathrm{j}-1}-\mu_{\mathrm{I}}\right)\right] \\
= & -\mathrm{E}\left(\mathrm{D}_{\mathrm{j}-1}-\mu_{\mathrm{D}}\right)\left(\mathrm{D}_{\mathrm{j}-1}-\mu_{\mathrm{D}}\right) \\
= & -\sigma_{\mathbf{D}}^{2}
\end{aligned}
$$

since, for independent random variables, $C$ and $D$, all the other expectations are zero. The lag zero covariance is defined:

$$
\begin{aligned}
\gamma_{\mathrm{I}}(0)= & E\left[\left(\mathrm{I}_{\mathrm{j}}-\mu_{\mathrm{I}}\right)\left(\mathrm{I}_{\mathrm{j}}-\mu_{\mathrm{I}}\right)\right] \\
= & \sigma_{\mathrm{I}}^{2} \\
= & \mathrm{E}\left[\left(\mathrm{C}_{\mathrm{j}}-\mathrm{D}_{\mathrm{j}-1}+\mathrm{D}_{\mathrm{j}}-\mu_{\mathrm{I}}\right)\right. \\
& \left.\cdot\left(\mathrm{C}_{\mathrm{j}}-\mathrm{D}_{\mathrm{j}-1}+\mathrm{D}_{\mathrm{j}}-\mu_{\mathrm{I}}\right)\right] \\
= & \sigma_{\mathrm{C}}^{2}+2 \sigma_{\mathrm{D}}^{2} .
\end{aligned}
$$

Thus, for the two-process timing mechanism, the lag one serial correlation is given by:

$$
\rho_{\mathrm{I}}(1)=-\frac{1}{2+\left(\frac{\sigma_{\mathrm{C}}^{2}}{\sigma_{\mathrm{D}}^{2}}\right)}
$$

Equation 4, which is formally equivalent to a result 
KEY. $C_{j}$ Interval between timekeeper trigger pulses
$D_{j}$ Response delay
$I_{j}$ Interresponse interval

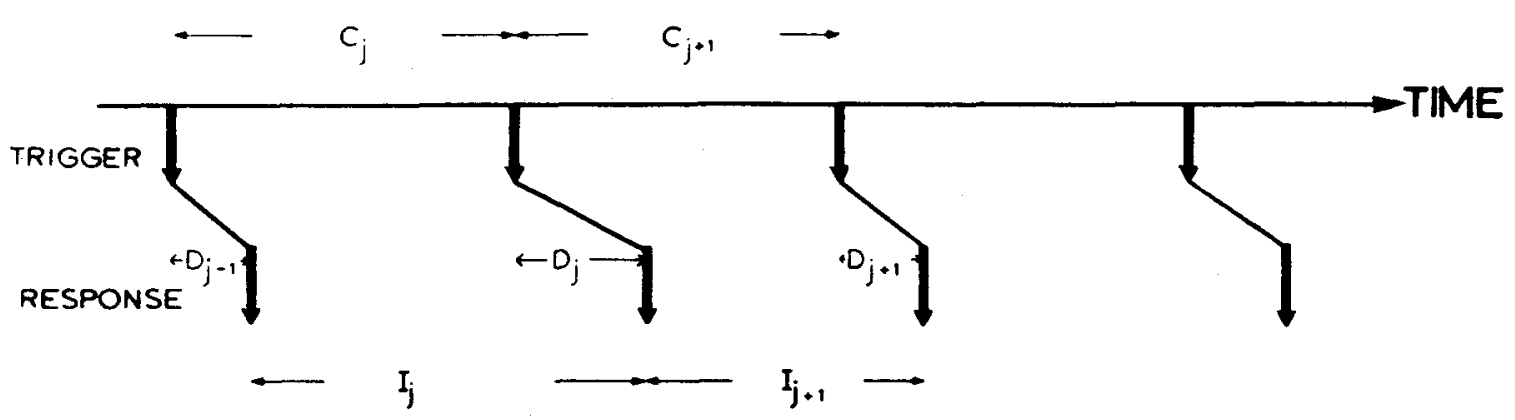

Fig. 1. Schematic of a two-process mechanism for the timing of repetitive discrete motor responses.

derived by Ten Hoopen and Reuver (1967), is important for the reason that it demonstrates that negative dependence between successive intervals in a response timing task need not be a result of the feedback of temporal information from the previous interresponse interval in the production of the current interval. While we could not reject a feedback interpretation if negative lag one serial correlation is found in interval production tasks, the important point is that a simpler alternative would be that such correlation is just an artifact of the delays in the system subsequent to the controlled timing of a particular interval. For example, the special case for which the timekeeper has no variability $\left(\sigma_{\mathrm{C}}^{2}=0\right)$ would lead to $\rho_{\mathrm{I}}(1)$ of negative one half. On the other hand, a prediction of zero $\rho_{\mathrm{I}}(1)$ obtains if the timekeeper variance is very large $\left(\sigma_{\mathrm{C}}^{2} \gg \sigma_{\mathrm{D}}^{2}\right)$. Furthermore, if $\sigma_{\mathrm{C}}^{2}$ is intermediate with respect to these two extremes, a value would be expected for $\rho_{I}(1)$ in the range $0>\rho_{\mathrm{I}}(1)>-1 / 2$, depending on the ratio of the timekeeper variance to the variance of response delays.

Suppose interest is centered on possible mechanisms for the timekeeper itself. An important clue to the nature of the timekeeper could be provided by its variability as a function of interresponse interval. Wing and Kristofferson (1973) have used estimates of $\sigma_{\mathrm{I}}^{2}$ as approximations to $\sigma_{\mathrm{C}}^{2}$, assuming that the contribution of $\sigma_{\mathrm{D}}^{2}$ to the overall variance is not a function of interresponse interval. Rather than making such an assumption, it would be preferable to make a direct determination of $\sigma_{\mathrm{C}}^{2}$. This may be done by using the following relation derived from Eqs. 2 and 3:

$$
\sigma_{\mathrm{C}}^{2}=\gamma_{\mathrm{I}}(0)+2 \gamma_{\mathrm{I}}(1)
$$

In this paper, the data of Wing and Kristofferson (1973) are subjected to the analysis suggested by Eq. 5 in order to examine the relation between interresponse interval and the variance of the timekeeper. Data from a previously unpublished experiment using different Ss and intervals in the range of $250.400 \mathrm{msec}$ are also reported.

\section{METHOD}

The procedure is fully described in Wing and Kristofferson (1973). In each session. Ss were exposed to five blocks of 11 sequences of combined paced and unpaced Morse keytapping using the right hand. After a warning signal, each sequence began with 24 auditory pulses of $10 \mathrm{msec}$ duration separated by fixed intervals of $(T-10) \mathrm{msec}$ with which $S$ attempted to synchronize his keytap responses. Following the last of the train of pulses in this synchronization phase, $S$ was required to continue tapping at the established, fixed rate for a further 31 responses. A warning signal sounded on the last response in this continuation phase to indicate to $S$ that he should stop. In any session, only one value of the standard, $T$, was used.

In Experiment I (hereafter referred to as Experiment $A_{1}$ ) of Wing and Kristofferson, six values of $T$ were used which ranged from 180 through $350 \mathrm{msec}$; at each $T$, prior to the four sessions from which data was taken for analysis, $S$ s were given six practice sessions. In their Experiment II $\left(\mathrm{A}_{2}\right)$, using the same four Ss, the three values of $T$ were 170,220 , and $270 \mathrm{msec}$, but only four practice sessions were given. Since the Ss appeared to be physically limited in responding at the fastest rate $(T=$ $170 \mathrm{msec}$ ), those data are not treated here. In the experiment not previously reported (B), four different Ss were run, using the same procedure with four practice sessions preceding data collection at six $T$ values from 250 to $400 \mathrm{msec}$.

\section{RESULTS}

Analyses are based on the last 30 intervals recorded in the continuation phase of each of the sequences run in the last four sessions at each $T$ value. Sequences in which "missed" or "bounced" key responses occurred were not included in the analysis. (Less than $5 \%$ of sequences for Ss in Experiments $A_{1}$ and $A_{2}$ had to be rejected; a slightly higher percentage of sequences in Experiment B could not be used on this basis.) 
Estimates of $\rho_{\mathrm{I}}(1)$ were based on the value of $\mathrm{P}_{\mathrm{I}}(1)$ averaged over all sequences at a given value of $T$ where:

$$
P_{I}(1)=\frac{G_{I}(1)}{G_{I}(0)}
$$

with

$$
G_{I}(1)=\frac{\sum_{j=2}^{N}\left(I_{j}-\bar{I}\right)\left(I_{j}-1-\bar{I}\right)}{N-1}
$$

and

$$
G_{I}(0)=\frac{\sum_{j=1}^{N}\left(I_{j}-\bar{I}\right)^{2}}{N}
$$

where

$$
\bar{I}=\frac{\sum_{j=1}^{N} I_{j}}{N} \text {, and } N=30 \text {. }
$$

The estimators for $\sigma_{\mathrm{C}}^{2}$ and $\sigma_{\mathrm{D}}^{2}$ were based on the values of $S_{C}^{2}$ and $S_{D}^{2}$, respectively, averaged over all sequences at a given value of $T$ :

$$
\begin{aligned}
& S_{C}^{2}=G_{I}(0)+2 G_{I}(1) \\
& S_{D}^{2}=-G_{I}(1)
\end{aligned}
$$

\section{Experiment A}

Changes in $\bar{I}$ and $P_{I}(1)$ within sequences were small, as determined by averaging over sequences the differences between the statistics calculated for the first 15 and the second 15 interresponse intervals of each sequence. These are shown for M.F. in Table 1. There was no obvious effect of $T$ on these differences for the four Ss, and their results, pooled over $T$ values, are given in Table 2. Since the assumption of stationarity in the underlying data generating process appears to be a reasonable approximation, we do not remove long-term trends in the data before calculating $\mathrm{G}_{\mathrm{I}}(1)$ and $\mathrm{G}_{\mathrm{I}}(0)$.

Figure 2 shows, for each $S, \bar{P}_{I}(1)$ as a function of the overall mean interresponse interval for Experiments $A_{1}$ and $A_{2}$. On the basis of the variance of the $P_{I}(1)$, two standard errors of the statistic about zero correlation are shown for M.F. These were typical of the errors for the other three Ss. The estimates of the lag one serial correlation are all in the range of $0>\overline{\mathrm{P}}_{\mathrm{I}}(1)>-1 / 2$.

The estimates of $\sigma_{\mathrm{C}}^{2}$ and $\sigma_{\mathrm{D}}^{2}$ are shown for each $\mathrm{S}$ in Figs. 3-6 as a function of interresponse interval. Best fit
Table 1

Change in Mean and Lag One Serial Correlation Coefficient for S M.F. in Experiment A $+(+$ Sign Indicates Increase in Absolute Magnitude)

\begin{tabular}{lcccc}
\hline & \multicolumn{4}{c}{ Standard (msec) } \\
\cline { 2 - 5 } & 180 & 220 & 270 & 350 \\
\hline Change in $\overline{\mathrm{I}}(\mathrm{msec})$ & +1.23 & +2.10 & +0.17 & +0.54 \\
SD (msec) & 2.12 & 2.11 & 2.50 & 3.44 \\
Change in $\mathrm{P}_{\mathrm{I}}(1)$ & -0.031 & -0.039 & -0.042 & +0.012 \\
SD & 0.317 & 0.338 & 0.316 & 0.292 \\
$\mathrm{~N}$ & 212 & 209 & 203 & 209 \\
\hline
\end{tabular}

Table 2

Change in Mean and Lag One Serial Correlation Coefficient Averaged Over Eight Values of $T$ from 180 through $350 \mathrm{msec}$ in Experiment $A$ (+ Sign Indicates Increase in Absolute Magnitude)

\begin{tabular}{lcccc} 
& \multicolumn{4}{c}{ Subject } \\
\cline { 2 - 5 } & A.W. & J.W. & I.T. & M.F. \\
\hline Change in $\bar{I}(\mathrm{msec})$ & +0.74 & +1.36 & +0.29 & +0.89 \\
Pooled SD (msec) & 2.22 & 2.16 & 3.20 & 2.48 \\
Change in P $_{\mathrm{I}}(1)$ & 0.000 & -0.011 & 0.011 & -0.030 \\
Pooled SD & 0.316 & 0.318 & 0.319 & 0.324 \\
\hline
\end{tabular}

straight lines to the estimates of the form $\left.\overrightarrow{\mathrm{S}}_{\mathrm{C}}^{2}=\alpha \overline{(\mathrm{I}}-\beta\right)$ were determined by least squares, and in all cases the intercepts, $\alpha \beta$, are negative, such that the values of the intervals corresponding to zero variance, $\beta$, are in the range of $69-122 \mathrm{msec}$. The estimates, $\widehat{\mathrm{S}}_{\mathrm{D}}^{2}$, exhibit, in general, a minimum in the region of intervals corresponding to intermediate values of the standard, $T$.

\section{Experiment B}

Tables 3 and 4 summarize changes in $\bar{I}$ and $P_{I}(1)$ from first to second halves of each sequence. Again, we retain, as a first approximation, the assumption of stationarity.

$\overline{\mathrm{P}}_{\mathrm{I}}(1)$ is plotted as a function of mean interresponse interval for Experiment B in Fig. 7. Two standard errors about a serial correlation of zero are shown for C.Y. All estimates fall in the range $0>\overline{\mathrm{P}}_{\mathrm{I}}(1)>-1 / 2$.

Estimates, $\vec{S}_{D}^{2}$ (see Figs 8-11), were about twice the size of those obtained for the Ss of Experiment A. (Note that Fig. 11 is plotted on a variance scale which is twice that of the other plots). One S (B.B.) yielded $\bar{S}_{D}^{2}$, which increased monotonically with $\bar{I}$, while for the other $S$ s the estimates were an irregular function of $\overline{\mathrm{I}}$. Least squares best fit straight lines to $\bar{S}_{C}^{2}$ are shown and have intercepts $\beta$ in the range of $107-236 \mathrm{msec}$.

\section{DISCUSSION}

By analogy with accounts of performance in duration discrimination tasks, Wing and Kristofferson (1973) suggested two contrasting models for the relation between the variance in the timing of discrete motor 


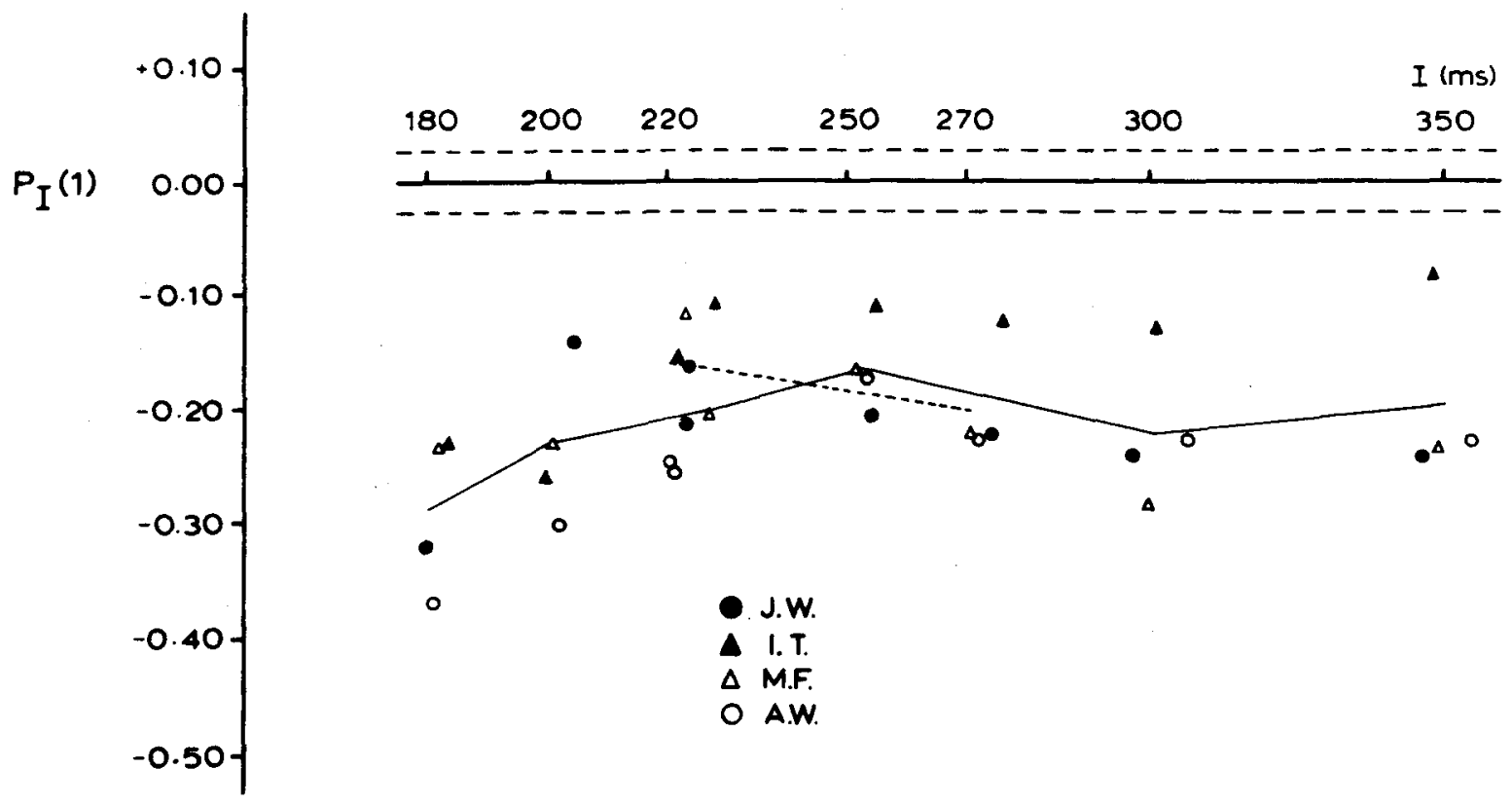

Fig. 2. Average lag one serial correlation, $\overline{\mathbf{P}}_{\mathbf{I}}(1)$, as a function of mean interresponse interval, $\overrightarrow{\mathrm{I}}$, for each $S$ in Experiment $A$. Two standard errors about zero shown for M.F. Average function over Ss for Experiment $A_{1}$ indicated by the continuous line and for Experiment $A_{2}$ shown by the broken line.

responses and the interval being produced between responses. On the one hand, they proposed (I) a timekeeper having variance so large with respect to the variance of the efferent delays that the latter could be

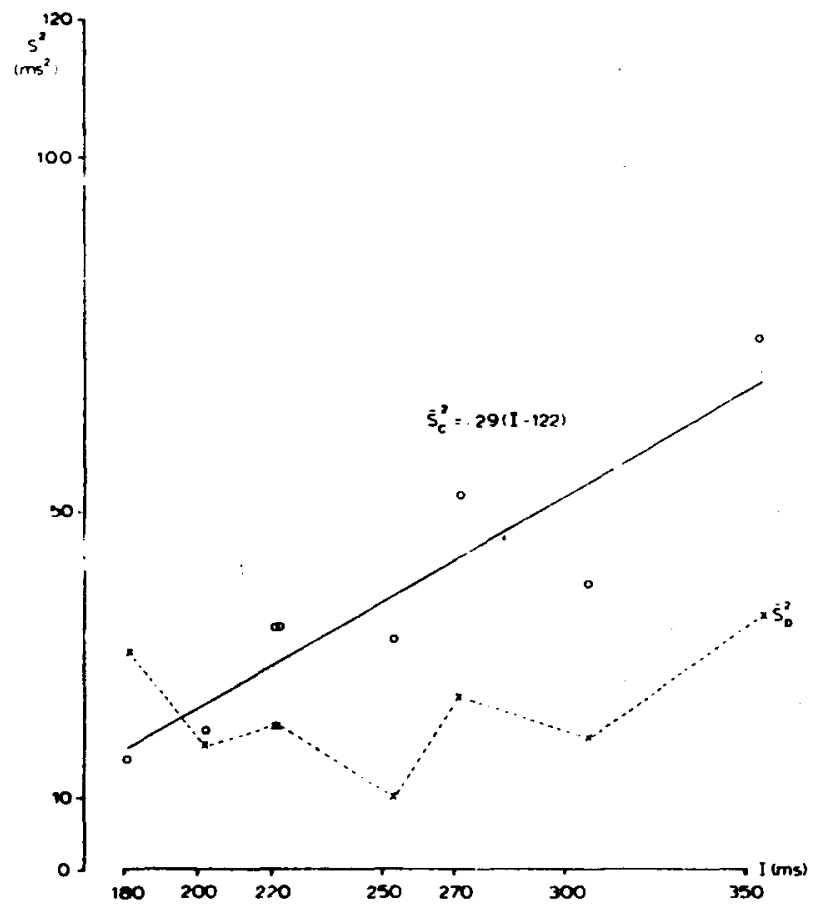

Fig. 3. Estimates of timekeeper interval variance, $\overline{\mathrm{S}}_{\mathbf{C}}^{2}$, and response delay variance, $\widehat{S}_{D}^{2}$, as a function of $\bar{I}$ for $A . W$. considered negligible. For the alternative (II), it was assumed that the timekeeper was essentially deterministic and that the interresponse interval variance was attributable entirely to the response delay variance.

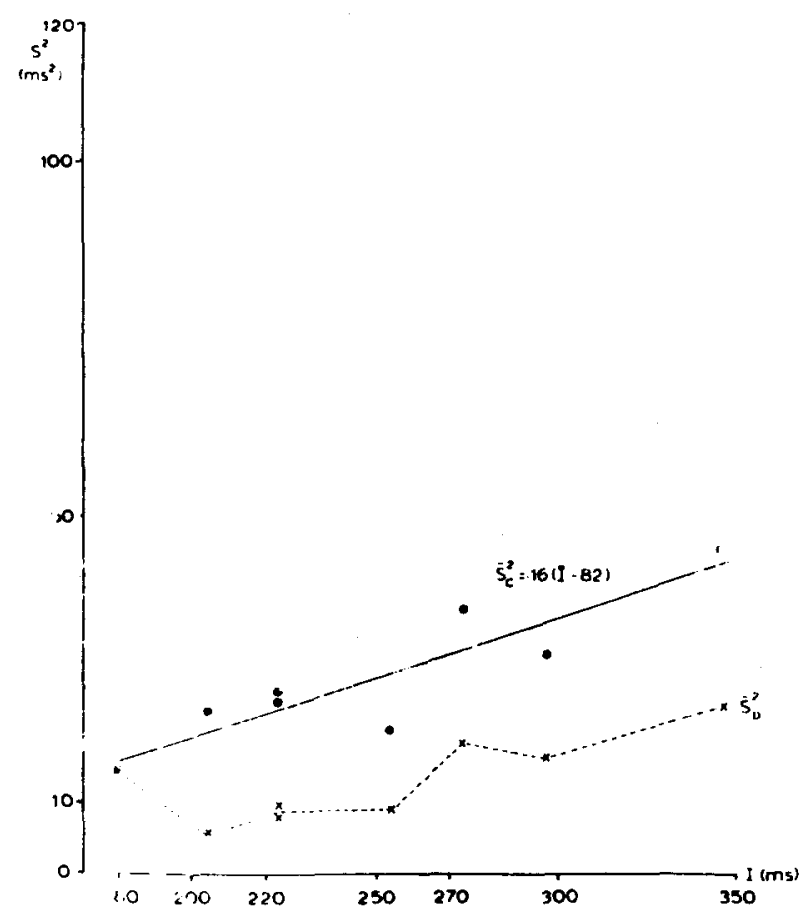

Fig. 4. $\overline{\mathrm{S}}_{\mathrm{C}}^{2}$ and $\overline{\mathrm{S}}_{\mathrm{D}}^{2}$ vs $\bar{I}$ for J.W. 


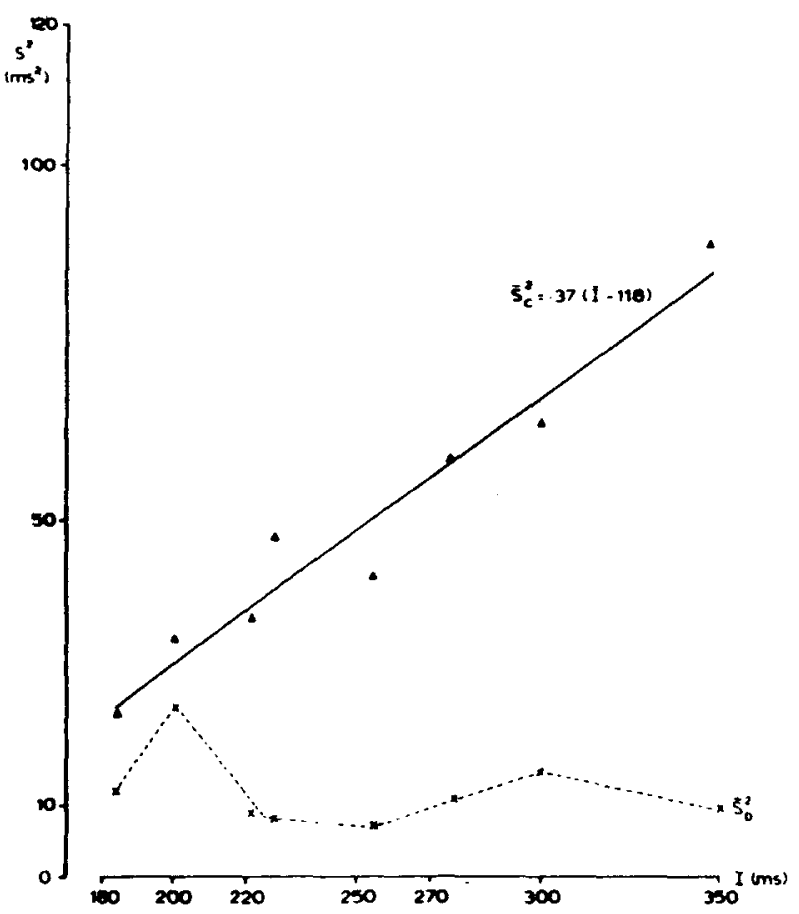

Fig. 5. $\overline{\mathrm{S}}_{\mathrm{C}}^{2}$ and $\overline{\mathrm{S}}_{\mathrm{D}}^{2}$ vs $\overline{\mathrm{I}}$ for I.T.

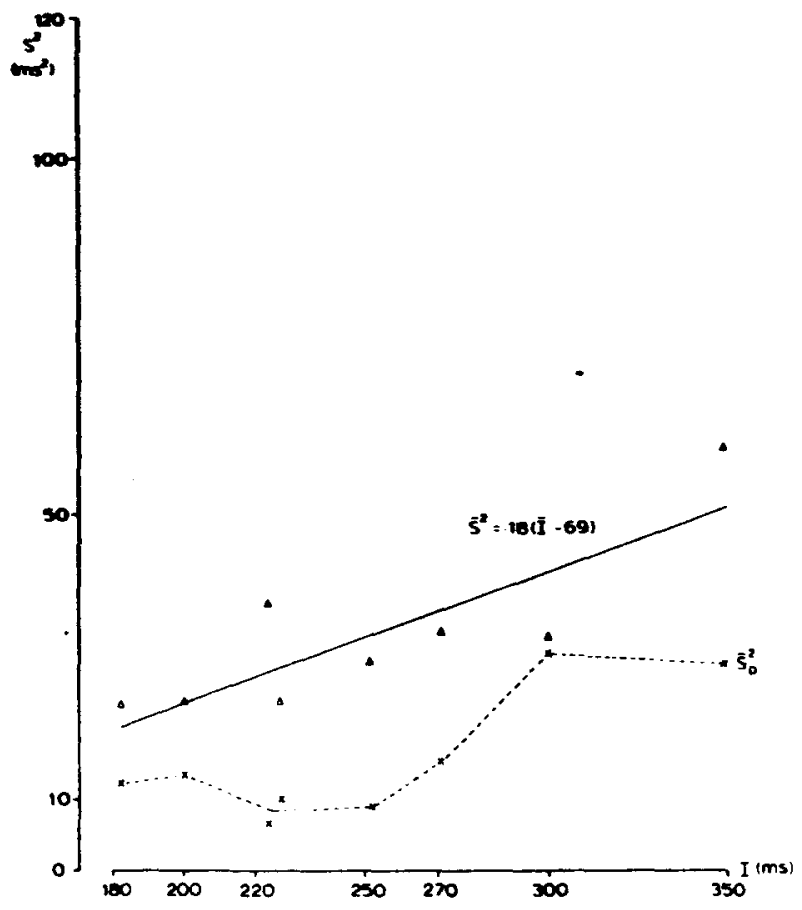

Fig. 6. $\overline{\mathrm{S}}_{\mathrm{C}}^{2}$ and $\overrightarrow{\mathrm{S}}_{\mathrm{D}}^{2}$ vs $\overline{\mathrm{I}}$ for M.F.

The additional assumptions were made that, for Model I, the variance of the timekeeper was a linear increasing function of interresponse interval but that, in II, the
Table 3

Change in Mean and Lag One Serial Correlation Coefficient for S C.Y. in Experiment B (+ Sign Indicates Increase in Absolute Magnitude)

\begin{tabular}{lccc}
\hline & \multicolumn{3}{c}{ Standard (msec) } \\
\cline { 2 - 4 } & 250 & 300 & 400 \\
\hline Change in $\overline{\mathrm{I}}$ (msec) & +0.06 & +0.89 & -3.92 \\
$\mathrm{SD}$ (msec) & 2.79 & 2.62 & 3.49 \\
Change in $\mathrm{P}_{\mathrm{I}}(1)$ & +0.033 & -0.046 & +0.017 \\
$\mathrm{SD}$ & 0.267 & 0.309 & 0.289 \\
$\mathrm{~N}$ & -204 & 193 & 181 \\
\hline
\end{tabular}

Table 4

Change in Mean and Lag One Serial Correlation Coefficient Averaged Over Six Values of $T$ from 250 through $400 \mathrm{msec}$ in Experimeat $B(+$ Sign Indicates Increase in Absolute Magnitude)

\begin{tabular}{lrrrc}
\hline & \multicolumn{4}{c}{ Subject } \\
\cline { 2 - 5 } & C.Y. & \multicolumn{1}{c}{ B.B. } & \multicolumn{1}{c}{ R.S. } & M.U. \\
\hline Change in $\bar{I}$ (msec) & -1.21 & -0.65 & -0.29 & 0.24 \\
Pooled SD (msec) & 2.82 & 3.49 & 3.62 & 5.51 \\
Change in $P_{I}(1)$ & -0.015 & -0.011 & +0.022 & -0.010 \\
Pooled SD & 0.275 & 0.298 & 0.324 & 0.328 \\
\hline
\end{tabular}

response delay variance was not a function of experimental condition (that is, response delay variance does not depend on the interresponse interval). Using the interresponse interval data analyzed as Experiment A in this paper, they showed that neither (I) nor (II) alone was adequate to account for the observed relation between interresponse interval mean and variance. Instead, they argued for a "combined" model, with both timekeeper and response delay processes contributing variance to the interresponse intervals. In the introduction of the present paper, a generalized development of this model was given and (I) and (II) will be seen as the special cases for which $\sigma_{\mathrm{C}}^{2} \gg \sigma_{\mathrm{D}}^{2}$ and $\sigma_{\mathrm{C}}^{2} \ll \sigma_{\mathrm{D}}^{2}$, respectively. From Eq. 4 , we could have predicted the lag one serial correlation for (I) as 0 and for (II) as $-1 / 2$. Since the estimates of the lag one serial correlation, $\overline{\mathbf{P}}_{\mathbf{I}}(1)$, are all intermediate in this range, we can thus reject both (I) and (II) without having to make the supplementary assumptions about how $\sigma_{\mathrm{C}}^{2}$ and $\sigma_{\mathrm{D}}^{2}$ depend on $\mu_{\mathrm{I}}$.

Within the framework of the general two-process model, we find the estimates, $\overrightarrow{\mathrm{S}}_{\mathbf{D}}^{2}$, are not constant over different values of $T$. However, if $\sigma_{D}^{2}$ includes variance attributable to skeletomuscular factors, since it may be supposed that the group of muscles involved in the keytapping response will operate more efficiently, and so with less variability, at certain rates of responding, irregularity in $\sigma_{\mathbf{D}}^{2}$ could be expected. If an account of the timekeeper is formulated in terms of a stochastic wait process for the production of the intervals. $C$. between trigger pulses. the expected relation 


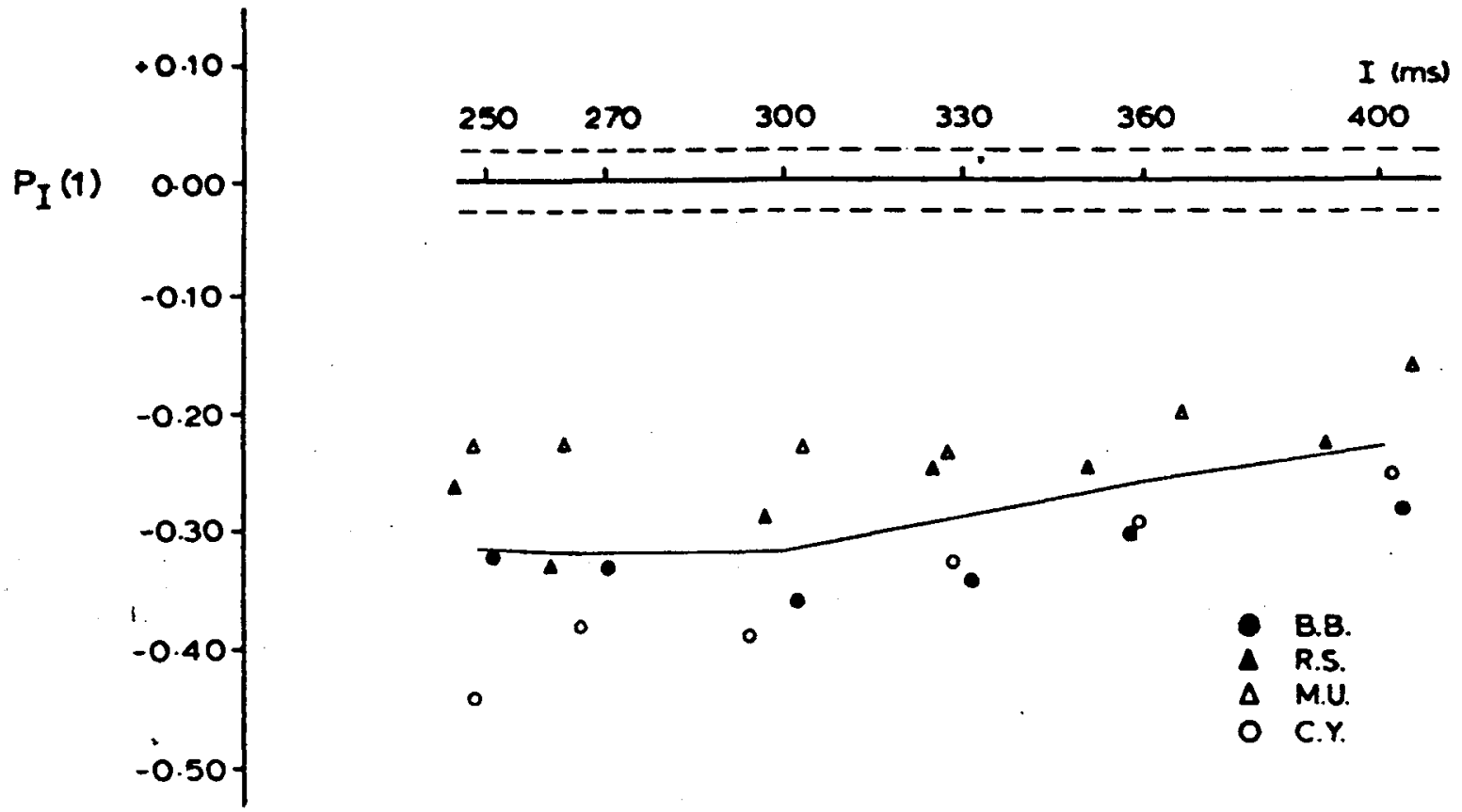

Fig. 7. $\overline{\mathrm{P}}_{\mathbf{I}}(1)$ vs $\overline{\mathrm{I}}$ for each $\mathrm{S}$ in Experiment B. Two standard errors about zero shown for C.Y.

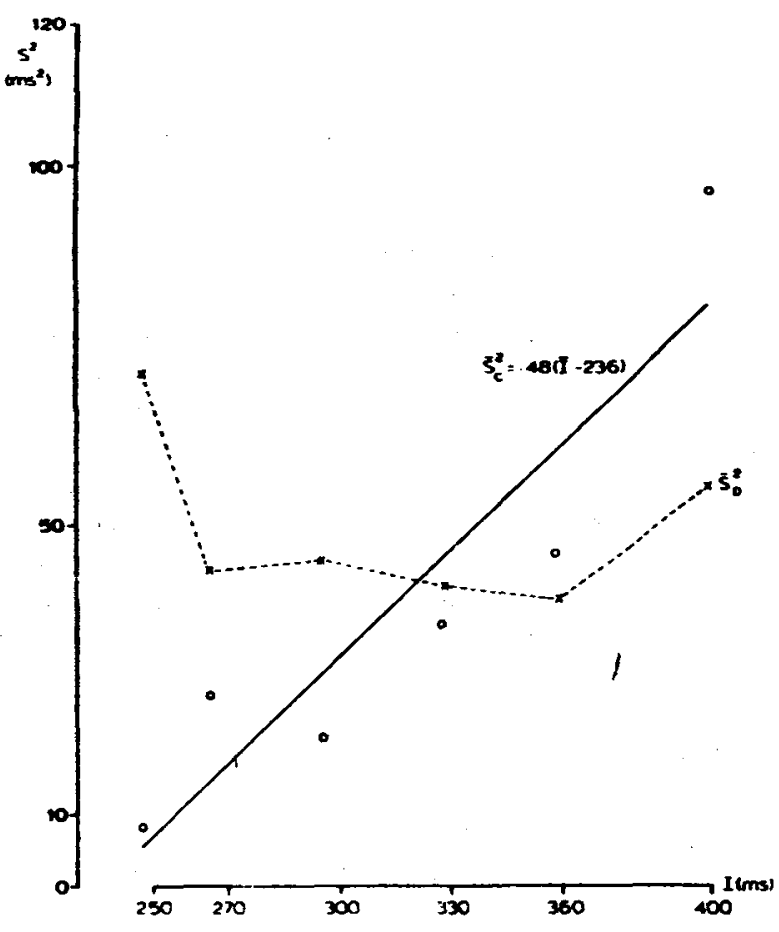

Fig. 8. $\overline{\mathrm{S}}_{\mathrm{C}}^{2}$ and $\overline{\mathrm{S}}_{\mathrm{D}}^{2}$ vs $\overline{\mathrm{I}}$ for C.Y.

between $\sigma_{\mathrm{C}}^{2}$ and $\mu_{\mathrm{I}}$ is a linear increasing function with zero intercept. However, for all Ss, it was found that the best fitting linear relation between $\overline{\mathrm{S}}_{\mathrm{C}}^{2}$ and $\overline{\mathrm{I}}$ has

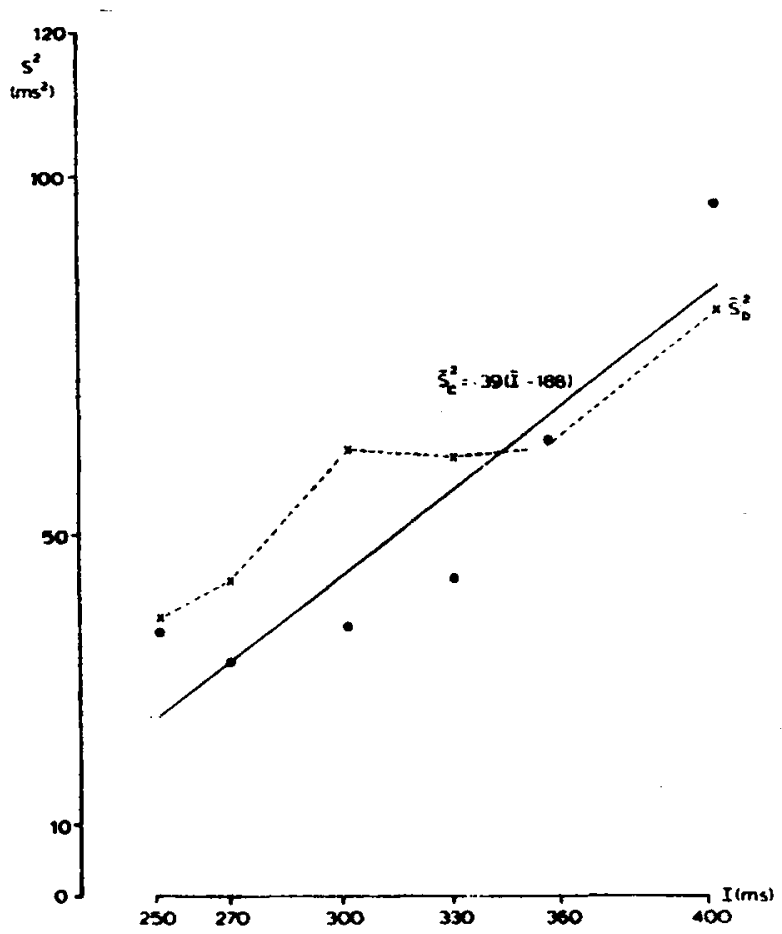

Fig. 9. $\overline{\mathrm{S}}_{\mathbf{C}}^{2}$ and $\overline{\mathrm{S}}_{\mathrm{D}}^{2}$ vs $\overline{\mathrm{I}}$ for B.B. intercept, $\beta$, on the I-axis greater than zero. Assuming the validity of the two-process response timing model, one possible account of nonzero $\beta$ is that the interval 
between trigger pulses is the sum of two quantities:

$$
C_{j}=R_{j}+W_{j}
$$

where $R$ is a random variable with fixed mean, $\mu_{R}$, and fixed variance, $\sigma_{R}^{2}$, and $W$ is the random variable (independent of $R$ ) defined on the waiting time such that $\sigma_{\mathrm{W}}^{2}$ is directly proportional to $\mu_{\mathrm{W}}$ (and thus to $\mu_{\mathrm{I}}$ ). In this case, the form of the $\sigma_{\mathrm{C}}^{2}$ vs $\mu_{\mathrm{I}}$ function, determined by $W$, is still linear, but the intercept, $\beta$, will depend on the parameters, $\sigma_{R}^{2}$ and $\mu_{R}$. It should be noted, in passing, that the quantity $R_{j}$ is not defined in such a way that it could be the output of a deterministic timekeeper such as in (II) above. Rather, it might be conceptualized as a "reset" time for the process, which subsequently determines the duration of the wait, $w_{j}$.

Whatever the true form of the $\sigma_{\mathrm{C}}^{\mathrm{C}}$ vs $\mu_{\mathrm{I}}$ relation, it would be a reasonable guess that, if Ss are required to produce longer interresponse intervals, $\sigma_{\mathrm{C}}^{2}$ will become more important relative to $\sigma_{\mathrm{D}}^{2}$ in the determination of $\rho_{\mathrm{I}}(1)$. If the value of $\sigma_{\mathrm{D}}^{2}$ remains constant as $\sigma_{\mathrm{C}}^{2}$ increases, a point would be reached for which $\rho_{\mathrm{I}}(1)$ is effectively zero. Michon (1967) has reported interval production data from a Morse keytapping task similar to the one used in this study with 200 intervals per sequence but with standards ranging from 333 to $3,333 \mathrm{msec}$. For a sample of eight sequences chosen at random from all standards and Ss, he reports that the lag one serial correlation estimate was not significantly

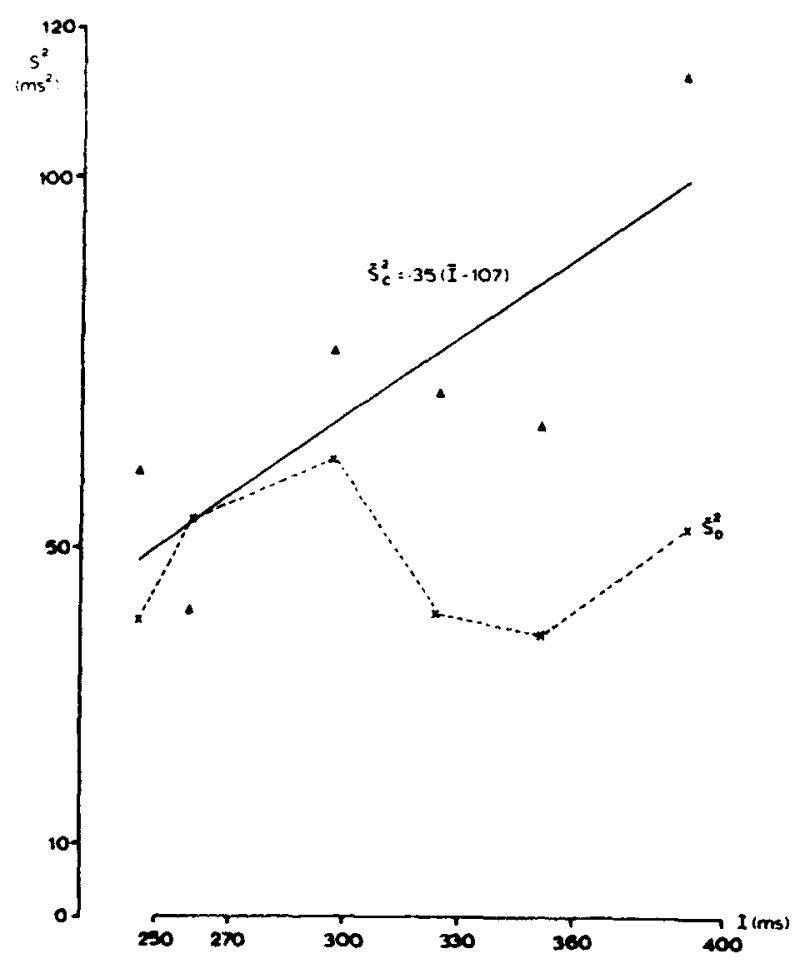

Fig. 10. $\bar{S}_{\mathrm{C}}^{2}$ and $\overline{\mathrm{S}}_{\mathrm{D}}^{2}$ vs $\overline{\mathrm{I}}$ for R.S.

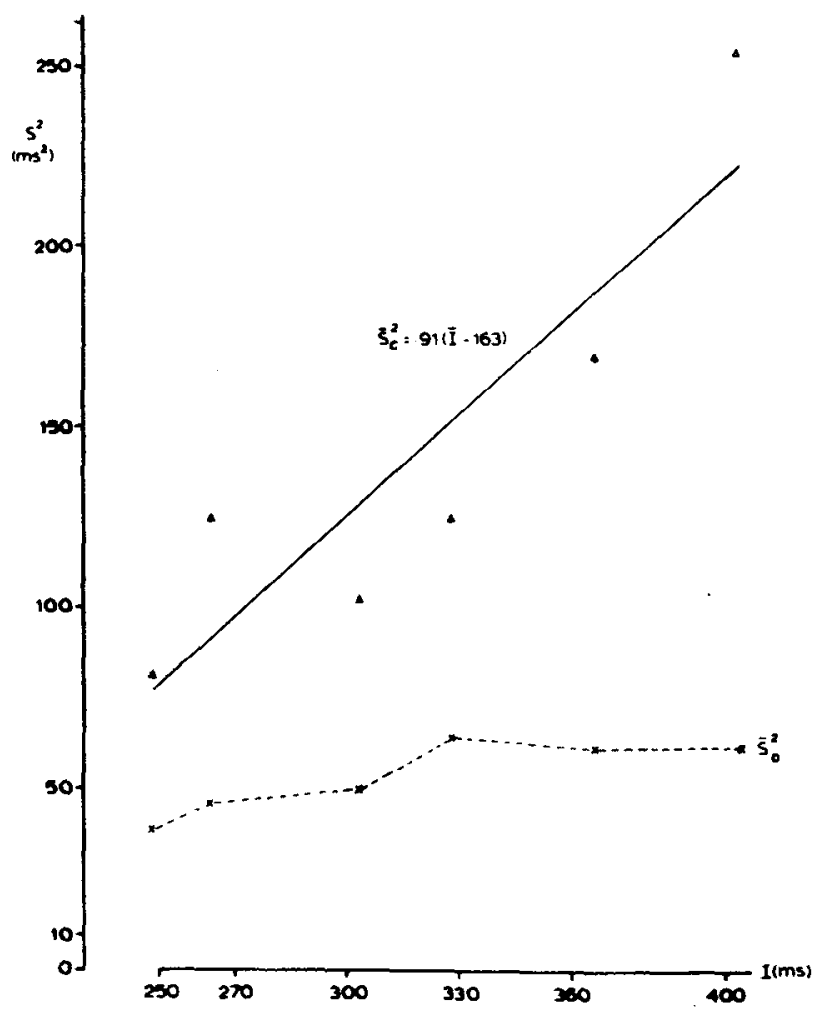

Fig. 11. $\overline{\mathrm{S}}_{\mathrm{C}}^{2}$ and $\overline{\mathrm{S}}_{\mathrm{D}}^{2}$ vs $\overline{\mathrm{I}}$ for M.U.

different from zero. While we should have been interested to know more precisely the effect of using longer standards, within the framework of the two-process response timing model, this result does at least suggest that the influence of variability in the response delays plays a less significant role at longer interresponse intervals.

The method derived from the two-process model for decomposing an overall interval variance, $\sigma_{\mathbf{1}}^{2}$, into the two variances, $\sigma_{\mathrm{C}}^{2}$ and $\sigma_{\mathrm{D}}^{2}$, may be contrasted with the approach sometimes taken in reaction time which treats the latency of response to a stimulus as the passage time through a series of processing stages, each with a characteristic distribution of delays. If it is assumed that the configuration is stable, that from trial to trial the same stages are involved, the overall latency distribution is given by the convolution of the component stage distributions. When specific assumptions are made about the latency distributions of a subset of stages (for example, those involved in making the sensory decision), the latency distribution of the remaining stages (which would include stages relating to response selection and initiation) can be determined by the use of Fourier transforms in performing the deconvolution (Green, 1971). In this paper, we have postulated interresponse intervals to be the convolution of three latencies arising from two major component processes or subsets of stages. However. the nature of the model adopted in this 
case permits the determination of a characteristic of the latency distributions of both the processes (i.e., the variances) without having to arbitrarily specify a value for the variance of one or the other. What justification is there for the analysis? Clearly, the general two-process mechanism as presented in the introduction provides a sufficient characterization of the formal requirements of a fixed-rate repetitive response task, and the experimental procedures chosen would be expected to maximize the chances that it provide an appropriate interpretation. (This does not exclude the need for more elaborate process models, including the feedback and use of temporal information in dynamic tasks such as temporal tracking or the synchronization of responses with a stimulus train; cf. Michon, 1967; Voillaume, 1971.) On the empirical side, the prediction that $\rho_{I}(1)$ lies within the range $0>\rho_{\mathrm{I}}(1)>-1 / 2$ was confirmed for all Ss. As support for the proposal of distinct timekeeping and response delay processes, an important result would be to show experimental factors which selectively influence $\sigma_{\mathrm{C}}^{2}$ and $\sigma_{\mathrm{D}}^{2}$. An alternative strategy for research into the two-process model would be to establish a general model with relaxed independence assumptions that holds under limiting conditions, for example, of very rapid responding, and then to show that, under the conditions of the experiments described here, the dependence parameters are zero so that the assumption of independence is adequate.

\section{REFERENCES}

Green, D. M. Fourier analysis of reaction time data. Behavior Research Methods \& Instrumentation, 1971, 3, 121-125.

McGill, W. J. Random fluctuations of response rate. Psychometrika, 1962, 27, 3-17.

Michon, J. A. Timing in temporal tracking. Soesterberg, The Netherlands: Institute for Perception RVO-TNO, 1967.

Ten Hoopen, M., \& Reuver, H. A. Analysis of sequences of events with random displacements applied to biological systems. Mathematical Biosciences, 1967, 1, 599-617.

Voillaume, C. Modeles pour l'étude de la régulation des mouvements cadences. L'Année Psychologique, 1971, 71, 347-358.

Wing, A. M., \& Kristofferson, A. B. The timing of interresponse intervals. Perception \& Psychophysics, 1973, 13, 455-460.

(Received for publication October 30, 1972; revision received February 26, 1973.) 